saturated and unsaturated hydrocarbons of the naphthenic or polynuclear type, and, to a limited extent, of paraffins and aromatic hydrocarbons.

The authors have made careful determinations of viscosity by a modified form of Ostwald apparatus, and discuss lubricating value in terms of this property and chemical composition. The desideratum for a lubricant appears to be low viscosity and good lubricating power, as the lubricant is concerned in the transformation of solid into liquid friction. On the other hand, the mysterious property known as "body" - that is, the power of maintaining a film (or film strength) between shaft and bearings-is a vital factor. This property of body seems to idepend on surface tension, and is not necessarily dependent on viscosity, but appears to be conneoted with molecular weight: The possible iso-colloid nature of heavy oils in explaining high viscosity is considered, and the view is put forward that if this is the true nature of such oils, the film strength may depend upon the relation of the two phases present in the oil.

The following are some of the authors' general conclusions :-Paraffinoid oils, though highly stable, have little lubricating value, and the smaller the hydrogen content, the greater the viscosity and durability; it is the polynuclear naphthenes, especially the unsaturated components, which confer viscosity and film strength; the higher fractions of petroleum contain such unsaturated members, which, when removed, exhibit lower density, lower viscosity, higher molecular weight, and, genenally, lower lubricating value.

It appears, then, that the true lubricant is an unsaturated compound possessing the charaoteristic attributes of such compounds, and this applies not only to hydrocarbons, but also to fatty oils, such as rape, castor, and olive oil; in other words, unsaturation is a feature of chemical activity which, in addition to colour, taste, smell, and physiological properties, manifests itself in lubricating value. Moreover, the colloidal condition of a good lubricant may also have to be taken into consideration.

The whole subject of liquid lubricants is an important one, and in the above brief summary the authors have brought forward a contribution of a highly suggestive character, which emphasises very clearly the necessity' for further comprehensive and detailed study.

\section{STATISTICAL METHODS APPLIED TO PRACTICAL PROBLEMS.}

$W^{E}$ have received a copy of the presidential address delivered before the Indian Science Congress at Lahore in January last by Sir G. T. Walker, Director-General of Observatories, India (Calcutta: Thacker, Spink, and Co.). The bulk of the address is devoted to illustrating the application to important practical problems of statistical methods. Illustrations are given of the use of coefficients of correlation in connection with crop prediction, and also to show the extent of co-variation between the fever rate, population, cost of rice, cultivated area, and rainfall, so far as this can be determined by a first-degree regression equation computed from the data of twentyfive years.

An interesting point is the apparently close association between an increase of population and an increase of fever. Sir G. T. Walker observes that this "is so directly opposed to widely accepted medical ideas that for some months I did not treat it seriously. But on my informing Major McKendrick, of Kasauli, of it he urged me not to reject it lightly, and directed my attention to some analysis of his which would suggest an explanation. I have therefore examined the correNO. 2533 , VOL. IOI] sponding relationship for all the ten provinces of India for which sufficient data are available, and have not found a single negative coefficient. The average value is +0.5 . For those of you who are interested in sanitary matters I may briefly explain that the spread of malaria among men depends upon the meeting of healthy men with infected mosquitoes, and the spread among mosquitoes on the encounters between infected men and healthy mosquitoes; hence the relations are symmetrical from the mathematical, if not the æesthetic, point of view, and an increase in the number of men has essentially the same bad effect as an increase in the number of mosquitoes."

In view of the work which has been done, upon the method of variate difference correlation during recent years, it would be of interest further to explore the association by the new method. Statisticians in this country will appreciate the concluding passage of Sir G. T. Walker's address :- "I hope that statistical methods may before long be recognised as essential for efficiency for the following reasons. First, a table of data covering. say, fifty years gives any intelligent man the same advantage as if he had carefully watched the conditions for fifty years and had a perfect memory secondly, employing a draughtsman to plot these data will suggest relationships in a manner which would otherwise require profound study of the figures; and thirdly, employing a clerk to work out the correlation coefficients and regression equation will give him without effort trustworthy information about their relationships which will distinguish direct from indirect effects, and could be got in no other way."

\section{METHODS OF GAS WARFARE.}

THE issue of the Journal of the Washington Academy of Sciences for February 4 last, includes a report of a lecture by Prof. S. J. M. Auld, of the British Military Mission, on "Methods of Gas Warfare," delivered before the Academy. Naturally in the fecture, which is here summarised, attention is confined to a description of what the Germans have been doing; nothing is said of the activities of the Entente Powers in this direction.

The first gas attack was made by the Germans in April, 19I5, and the whole method of the war was changed. The attack was made, of course, against men who were entirely unprepared-absolutely unprotected. The Germans expected no immediate retaliation, as they had provided no protection for their own men. A clear and unobstructed gap in the lines was made, which was only closed by the Canadians, who rallied on the left and advanced, in part through the gas-cloud itself.

The method first used by the Germans is simple, but requires great preparation beforehand. A hole is dug in the bottom of the trench close underneath the parapet, and a gas cylinder is buried in the hole. It is then covered first with a quilt of moss containing potassium carbonate solution, and then with sandbags. When the attack is to be made the sand-bags are taken off the cylinder, and each cylinder is connected with a lead pipe which is bent over the top of the parapet. A sand-bag is laid on the nozzle to prevent the back "kick" of the outrushing gas from throwing the pipe back into the trench.

The attackers must know the direction and velocity of the wind with certainty. Favourable conditions are limited practically to wind velocities between twelve and four miles an hour. A wind of more than twelve miles an hour disperses the gas-cloud very rapidly. An upward current of air is the worst foe of gas. If the trench line is very irregular it is likely that gas will flow into a portion of one's own trenches. The 